\title{
Fipronil resistance in Sogatella furcifera: Molecular cloning and functional expression of wild-type and mutant RDL GABA receptor subunits
}

\author{
Toshifumi Nakao, ${ }^{*}$ Masako Hama, Nobuyuki Kawahara and Kangetsu Hirase \\ Agrochemical Research Center, Mitsui Chemicals Agro, Inc., Mobara, Chiba 297-0017, Japan
}

(Received August 24, 2011; Accepted October 18, 2011)

\begin{abstract}
The whitebacked planthopper Sogatella furcifera is a serious pest of rice that has developed fipronil resistance in Asia. We found a novel R340Q mutation in the cytoplasmic loop between M3 and M4 of the S. furcifera RDL $\gamma$-aminobutyric acid (GABA) receptor subunit (SF-RDL). The R340Q mutation was found in clones carrying the $\mathrm{A} 2^{\prime} \mathrm{N}$ mutation, which was previously implicated in fipronil resistance and suggested to be a heterozygous mutation. To investigate the influence of mutations, Drosophila Mel-2 cells were transfected with wild-type or mutant SF-RDL genes, either individually or together. A membrane potential assay showed that the influence of the $\mathrm{A} 2^{\prime} \mathrm{N} \cdot \mathrm{R} 340 \mathrm{Q}$ double mutation on fipronil resistance was more profound than that of the A2 $\mathrm{N}$ single mutation in the heterozygous expression of wild-type and mutant SF-RDL genes. () Pesticide Science Society of Japan

Keywords: GABA receptor, whitebacked planthopper, Sogatella furcifera, fipronil resistance.
\end{abstract}

\section{Introduction}

Fipronil and cyclodienes are noncompetitive antagonists for the insect ionotropic $\gamma$-aminobutyric acid (GABA) receptor. The GABA receptor is a ligand-gated chloride channel, and inhibition of the GABA-induced influx of chloride ions into the nerve cells results in hyperexcitation of the nervous system. The insect GABA receptor subunit gene was first cloned from Drosophila melanogaster and designated $R d l$ (resistant to dieldrin). ${ }^{1)}$ The GABA receptor consists of five subunits; each subunit contains a large extracellular agonist-binding N-terminal domain and four membrane-spanning regions (M1-M4). Alternatively spliced exons ( $3 \mathrm{a}$ or $3 \mathrm{~b}$ and $6 \mathrm{c}$ or $6 \mathrm{~d}$ ) were reported in $D$. melanogaster $R d l$ by ffrench-Constant and Rocheleau. ${ }^{2}{ }^{2}$ Alternative splicing produces four variants: ac-, ad-, bc-, and bd-types.

Several noncompetitive antagonists for the GABA receptor, including fipronil and cyclodienes, have been suggested to bind to a site within the pore formed by the membrane-spanning region M2. A2', T6 $^{\prime}$, and $\mathrm{L}^{\prime}$ ' (index number for the M2 membrane-spanning region) ${ }^{3)}$ are particularly important for their binding. ${ }^{4-6)}$ An A2'S mutation in M2 confers resistance to the cyclodienes in D. melanogaster. ${ }^{7)}$ In this study, the index number for the M2 membrane-spanning region was used to aid in the comparison of M2 mutations in the GABA receptors

\footnotetext{
* To whom correspondence should be addressed.

E-mail: Toshifumi.Nakao@mitsui-chem.co.jp

Published online February 6, 2012

(C) Pesticide Science Society of Japan
}

from various species. The A2'S mutation of the RDL GABA receptor corresponds to the A302S mutation of the Drosophila $R d l$ gene.

Until recently, two amino acid substitutions (A2'S and $A 2^{\prime} G$ ) have been reported to associate with cyclodiene resistance in various insect species. ${ }^{7-13)}$ Hope et al. ${ }^{14)}$ reported that the $\mathrm{T} 6^{\prime} \mathrm{L}$ mutation was associated with dieldrin resistance in the cattle tick Rhipicephalus (Boophilus) microplus. Although $A 2^{\prime} \mathrm{S}$ and $A 2^{\prime} \mathrm{G}$ mutations show cross-resistance to fipronil, the level of resistance is low. ${ }^{11)} \mathrm{A}$ double mutation $\left(\mathrm{A} 2^{\prime} \mathrm{G}\right.$ and T351M) profoundly decreased the antagonist activity, but it was observed only in selected fipronil-resistant $D$. simulans in the laboratory. ${ }^{15)}$

The whitebacked planthopper Sogatella furcifera and the small brown planthopper Laodelphax striatellus are serious insect pests of rice. They have developed resistance to fipronil and cause serious damage to the rice in Asia. ${ }^{16-19)}$ In a previous study, the $\mathrm{A} 2^{\prime} \mathrm{N}$ mutation was associated with fipronil resistance and was suggested to be a heterozygous mutation in S. furcifera ${ }^{20)}$ and L. striatellus. ${ }^{21)}$ A membrane potential assay showed that the $A 2^{\prime} \mathrm{N}$ mutation in the L. striatellus $\mathrm{RDL}$ GABA receptor subunit (LS-RDL) confers fipronil resistance in the heterozygous expression of wild-type and $\mathrm{A} 2^{\prime} \mathrm{N}$ mutant LS-RDL genes. ${ }^{21)}$ In this study, we used heterozygous expression and heterozygous receptors to indicate GABA receptors expressed on co-transfected cells with an equal amount of wild-type and mutant genes. This notation was used to facilitate the description of the GABA receptors expressed on cotransfected cells, and no genetic mechanism or specific assembly patterns were implied. 
In this study, we cloned full-length cDNAs encoding the $S$. furcifera RDL GABA receptor subunit (SF-RDL) and found a novel R340Q mutation in SF-RDL from fipronil-resistant $S$. furcifera. This mutation was associated with the $\mathrm{A} 2^{\prime} \mathrm{N}$ mutation. Although mutations in the M2 membrane-spanning region, such as $\mathrm{A} 2^{\prime} \mathrm{S}, \mathrm{A} 2^{\prime} \mathrm{G}, \mathrm{A} 2^{\prime} \mathrm{N}$, and $\mathrm{T} 6^{\prime} \mathrm{L}$, have been reported previously, this is the first finding of the R340Q mutation in the cytoplasmic loop between M3 and M4. In addition, we showed that the influence of the A2' $\mathrm{N} \cdot \mathrm{R} 340 \mathrm{Q}$ double mutation on fipronil resistance is more profound than that of the single $\mathrm{A} 2^{\prime} \mathrm{N}$ mutation in the heterozygous expression of wildtype and mutant SF-RDL genes.

\section{Materials and Methods}

\section{Insects}

One population of S. furcifera, resistant to fipronil, was collected from a paddy rice field in Fukuoka Prefecture in Japan in August, 2007, as described previously. ${ }^{20)}$ A fipronil-susceptible strain of $S$. furcifera is the laboratory strain maintained at the Agrochemical Research Center, Mitsui Chemicals Agro, in Japan. Insects were reared on rice seedlings at $25^{\circ} \mathrm{C}$ under a 16:8 light: dark regime and frozen before RNA was isolated.

\section{Chemicals}

GABA was purchased from Wako Pure Chemical Industries, Ltd. (Osaka, Japan). Fipronil (92.8\%) was synthesized at the Agrochemical Research Center, Mitsui Chemicals Agro (Mobara, Chiba, Japan).

\section{Isolation of full-length $c D N A$ clones encoding SF-RDL}

The isolation of total cellular RNA from fipronil-susceptible and -resistant $S$. furcifera and the sequencing of about 0.9-kbp DNA fragments encoding the M1-M3 membrane-spanning region of SF-RDL were described previously. ${ }^{20)}$

To obtain the $3^{\prime}$ and $5^{\prime}$ ends of a cDNA encoding SF-RDL, a SMARTer ${ }^{\mathrm{TM}}$ RACE cDNA amplification kit (Clontech Laboratories, Inc., Mountain View, CA, USA) was used according to the manufacturer's instructions. The $3^{\prime}$ end of the cDNA was amplified using nested PCR following RT-PCR. The primers used for the first PCR were a universal primer A mix (UPM) from the kit and a specific primer 5'Sf-1 (CAAACAGTACGCTTCAAGGT). For the nested PCR, the primer set, nested universal primer A (NUP)/5'SfSal (ACACTGATGTCGTCGACGAAC) or NUP/Seji 5'-1 (AGTTCGTGCGCTCGATGGGTTAT), was used. The $5^{\prime}$ end of the cDNA was amplified by RT-PCR. PCR was performed using the primer UPM and the specific primer SfRD-RT (CGGGCCCTCATTCCATTTATA). The PCR products were cloned into the plasmid pCR2.1 TOPO-Vector (Invitrogen, Carlsbad, CA, USA), and the sequences were determined. To isolate a full-length cDNA encoding SF-RDL, PCR and nested PCR were performed. The primers used for the first PCR included 5'Sf-1 (GTGCAATGGAGACCTGTGATC) and 3'Sf-1 (CCTTTCGACTAAATCGTCATC). The primer set, 5'Sf-2 (GTGATCGGCGCTGTT-
GACAAG)/-3'Sf-2 (CAGGATTAAGTCAGCTTAGGT) or 5'Sf (ATGAGCCGAGCGTTGGCCTTG)/-3'Sf-2, was used for the nested PCR. PCR products were cloned into the plasmid pCR2.1 TOPO-Vector, and the sequences were determined.

\section{Construction of vectors to express wild-type and mutant SF- RDL homomers}

To construct vectors to express the bd-type SF-RDL, three DNA fragments coding for the N-terminal, central, and C-terminal regions were amplified. The PCR fragment coding for the N-terminal was prepared using the primers BaSf5' (TTTGGATCCAAAAAACCTATAAAATGAGCCGAGCGTTGGCCTTG) and SfRD-RT and digested with BamHI and Hind III. The PCR fragments coding for the central region were amplified using the primers 5'Sf-Hin (ATAGAAAGCTTTGGGTATACCATGAGAGATATCCGCTA) and 3'Sf-SalXho (GTTCCTCGAGGACATCAGTGT). This PCR exchanged the SalI site for the XhoI site without changing the amino acid sequence, and the resulting fragment was digested with Hind III-XhoI. To introduce the A2' N mutation, the central region was amplified from the full-length cDNA containing the $\mathrm{A} 2{ }^{\prime} \mathrm{N}$ mutation and was used in place of the wild-type central region. To construct the wild-type SF-RDL gene, the DNA fragment encoding the C-terminal was amplified by PCR and nested PCR. The primers used for the first PCR included 5'Sf-Sal (ACACTGATGTCGTCGACGAAC) and Sf3' flag11 (ATCGTCATCCTTGTAGTCTTTGTCTTCTTCGAGCAG). The primers used for the nested PCR included 5' -Sf-Sal and Sf3'-flag12 (TTTTGCGGCCGCCTACTTGTCATCGTCATCCTTGTAGTC). For the construction of mutant SF-RDL genes, the DNA fragment encoding the C-terminal was amplified by PCR and nested PCR. The primers used for the first PCR included 5'Sf-Sal and Sf3'-V5-1 (AGGGTTAGGGATAGGCTTACCTTTGTCTTCTTCGAGCAG). The primers used for the nested PCR were 5' -Sf-Sal and Sf3'-V5-2 (TTTTGCGGCCGCCTACGTAGAATCGAGACCGAGGAGAGGGTTAGGGATAGGCTTACC). The fragment coding for the Cterminal region carrying the R340Q mutation was amplified from the cDNA containing the R340Q mutation and was used in place of the wild-type C-terminal region to introduce the R340Q mutation. The amplified DNA fragments were digested with Sal I and Not I. The sequences of the amplified DNA were verified by sequencing. Three DNA fragments encoding the $\mathrm{N}$-terminal, central, and C-terminal regions were then inserted into the BamHI-Not I site of pENTR1A (Invitrogen, Carlsbad, CA, USA). The resulting plasmid containing the wildtype SF-RDL gene was designated pENTR1A-Sf-RDL. The resulting plasmids containing $\mathrm{A} 2^{\prime} \mathrm{N}, \mathrm{A} 2^{\prime} \mathrm{N} \cdot \mathrm{R} 340 \mathrm{Q}$, and R340Q mutations were designated pENTR1A-Sf-RDL $\left(\mathrm{A} 2^{\prime} \mathrm{N}\right)$, pENTR1A-Sf-RDL (A2'N-R340Q), and pENTR1A-Sf-RDL (R340Q), respectively. The plasmid pAc5.1-lac-Hygro ${ }^{22)}$ containing the bacterial hygromycin $\mathrm{B}$ phosphotransferase gene and attR1-lacZ $\alpha$-attR2 was used for the construction of a vector to express wild-type and mutant SF-RDL homomers. The 
lacZ $\alpha$ of pAc5.1-lac-Hygro was replaced with the wild-type SF-RDL gene or mutant SF-RDL genes using the Gateway cloning system (Invitrogen).

\section{Construction of vectors to co-express wild-type and mutant SF-RDL genes}

To co-express wild-type and mutant SF-RDL genes, the plasmid pENTR-pA-pAc ${ }^{21)}$ was used. The plasmid pENTR1A-SfRDL was digested with BamHI and Not I, and the BamHINot I fragment containing the wild-type SF-RDL gene was inserted into the BamHI-NotI site of pENTR-pA-pAc; the resulting plasmid was designated as pENTR pA-pAc-SfRDL. Next, pENTR1A-Sf-RDL (A2'N), pENTR1A-Sf-RDL (A2' $\mathrm{N} \cdot \mathrm{R} 340 \mathrm{Q})$, and pENTR1A-Sf-RDL (R340Q) were digested with SalI-XbaI, and the Sal I-XbaI fragments encoding the mutant SF-RDL gene were inserted into the Sal I-XbaI site of pENTR-pA-pAc-Sf-RDL. The lacZ $\alpha$ of pAc5.1-lac-Hygro was replaced with a DNA fragment containing the mutant and wild-type SF-RDL genes using the Gateway cloning system (Invitrogen).

6. Generation of cell lines stably expressing wild-type and mutant SF-RDL genes

Cell lines stably expressing wild-type and mutant SF-RDL genes were constructed according to the methods described previously. ${ }^{20)}$ In this study, $300 \mu \mathrm{g} / \mathrm{mL}$ of hygromycin was used for the selection and culture of stable cell lines.

\section{Membrane potential assay}

Cells that were transfected with wild-type and mutant SF-RDL genes were characterized using the FLIPR Membrane Potential Assay Kit (Molecular Devices Corp., Sunnyvale, CA, USA) according to the methods described previously. ${ }^{20)}$

For the antagonism assay, cells were incubated with antagonists for $1 \mathrm{hr}$. The $\mathrm{EC}_{80}$ concentration of GABA was then added to the cells. The $\mathrm{EC}_{80}$ concentrations of GABA for wild-type SF-RDL, A2'N SF-RDL, A2'N-R340Q SF-RDL, R340Q SFRDL, wild-type/A2'N SF-RDL, wild-type/A2'N·R340Q SF$\mathrm{RDL}$, and wild-type/R340Q SF-RDL were $1 \mu \mathrm{M}, 12 \mu \mathrm{M}, 16 \mu \mathrm{M}$, $3 \mu \mathrm{M}, 2 \mu \mathrm{M}, 3 \mu \mathrm{M}$, and $1 \mu \mathrm{M}$, respectively. Experiments were performed in duplicate at least three times for each compound.

\section{Results}

1. Isolation of cDNA clones encoding SF-RDL

Ten cDNA clones of SF-RDL were isolated from fipronil-susceptible $S$. furcifera and sequenced (GenBank accession no. AB617631). Sequencing of cDNAs revealed that the open reading frame consisted of $1,437 \mathrm{bp}$, and the deduced amino acid sequence of SF-RDL was composed of 479 amino acids with a molecular weight of 54,059 (Fig. 1A). Deletion of the Glu residue at position 383 was observed in wild-type SF-RDL as a variation.

Alternative splicing of exon 3 ( $a$ and b) and exon 6 ( $c$ and d) was reported in D. melanogaster Rdl..$^{2)}$ As shown in Fig. 1B, analysis of the nucleotide sequences from cDNA clones encoding SF-RDL showed the presence of three possible alternative splice forms in exon 3 (designated as $3 a, 3 b$, and $3 b^{\prime}$ ) and two such forms in exon 6 (designated as $6 \mathrm{c}$ and $6 \mathrm{~d}$ ).

The percent identity in the protein sequence between the deduced bd-type SF-RDL and bd-type D. melanogaster RDL GABA receptor subunit (GenBank accession no. NM_079267) is $80.8 \%$. The deduced bd-type SF-RDL shares $88.7 \%, 87.3 \%$, $88.6 \%, 80.8 \%, 85.7 \%, 79.6 \%, 80.6 \%, 84.9 \%, 82.5 \%, 80.5 \%$, $83.5 \%$, and $68.2 \%$ identity with $L$. striatellus, Tribolium castaneum, Ctenocephalides felis, Heliothis virescens, Plutella xylostella, Spodoptera exigua, D. simulans, Musca domestica, Lucilia cuprina, Aedes aegipti, Anopheles gambiae, and Rhiphicephalus microplus RDL GABA receptor subunits, respectively (GenBank accession nos. AB253526, NM_ 001114337, AX47745, AJ224513, EF156251, EF535530, AY017266, AB177547, AF024647, U28803, XM_001688723, and GQ39811, respectively).

The structural features of SF-RDL are similar to those of the RDL GABA receptor subunits from other species, including a putative signal sequence, a large extracellular agonist-binding $\mathrm{N}$-terminal domain, four membrane-spanning regions, and a large intracellular loop between M3 and M4.

\section{Fipronil resistance-associated mutations}

Total RNA was extracted from fipronil-resistant S. furcifera (about $50 \mathrm{mg}$ ) and cDNA clones encoding SF-RDL were isolated and sequenced. In a previous study, we observed the $\mathrm{A}^{\prime} \mathrm{N}$ mutation in the M2 of SF-RDL, which was suggested to be a heterozygous mutation that conferred fipronil resistance to $S$. furcifera. ${ }^{20)}$ In addition to the A2' $\mathrm{N}$ mutation, we found a novel R340Q mutation in the cytoplasmic loop between M3 and M4 (Fig. 1A). The R340Q mutation was only identified in clones carrying the $\mathrm{A} 2^{\prime} \mathrm{N}$ mutation. We found the R340Q mutation in 9 of $17 \mathrm{cDNA}$ clones carrying the $\mathrm{A} 2^{\prime} \mathrm{N}$ mutation. However, none of the $16 \mathrm{cDNA}$ clones which carried the Ala residue at the $2^{\prime}$ position contained the $\mathrm{R} 340 \mathrm{Q}$ mutation. Thus, we found two types of mutant clones. One clone carries the single $A 2^{\prime} \mathrm{N}$ mutation, and the other carries the A2' $\mathrm{N} \cdot \mathrm{R} 340 \mathrm{Q}$ double mutation.

In this study, we used about $50 \mathrm{mg}$ of $S$. furcifera to extract the total RNA. As the average body weight of insects is 1.17 $\mathrm{mg},{ }^{20)} 50 \mathrm{mg}$ of $S$. furcifera corresponds to about 40 insects. Thus, the results obtained here are expected to represent an average of 40 insects. Although we did not investigate the number of insects carrying the $\mathrm{A} 2^{\prime} \mathrm{N} \cdot \mathrm{R} 340 \mathrm{Q}$ mutation, it is likely that the $\mathrm{A} 2^{\prime} \mathrm{N} \cdot \mathrm{R} 340 \mathrm{Q}$ mutation is not rare and spreads among the fipronil-resistant $S$. furcifera investigated in this study.

In a previous study, the $\mathrm{A} 2^{\prime} \mathrm{N}$ mutation was suggested to be heterozygous. ${ }^{20)}$ It is likely that the native cells in fipronil-resistant S. furcifera co-express the wild-type/A2' $\mathrm{N}$ SF-RDL or wild-type/A2'N-R340Q SF-RDL genes. To study the native 
A

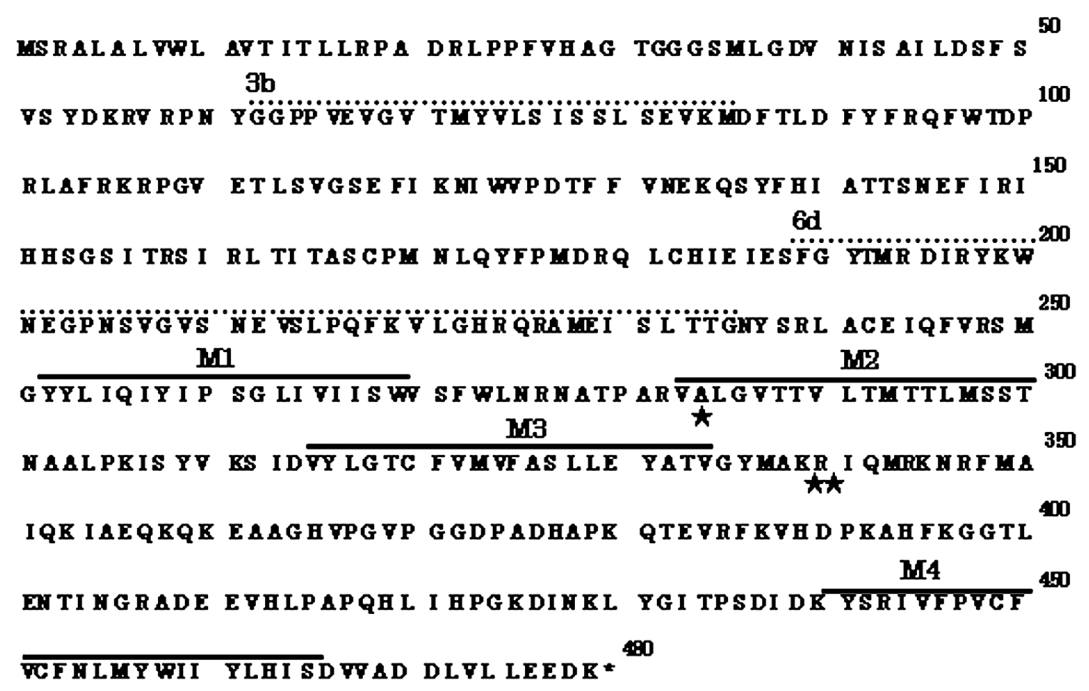

B

Possible alternative splicing

3a, $3 \mathbf{b}$, and $3 \mathbf{b}^{\circ}$

3a GGPPVEVGVTM YVLSISSESEVLM

3b GGPPVEVGVTM YVLSISSLSEVKM

$3 b^{\circ}$ GGPPVEVGVTMYVLSISSLSEVQMM

$6 c$ and $6 d$

6 c FGYTMRDIRYNWHAG

6 d FGYTM RDIRY KWNEGPNSVGVSNEV

Fig. 1. Amino acid sequences of the wild-type SF-RDL gene. (A) Complete amino acid sequence of the bd-type SF-RDL gene (GenBank accession no. AB617631). The four membrane-spanning regions (M1-M4) are overlined. Two possible alternative splice regions (3b and 6d) are indicated with a broken overline. The positions of mutations A2' and R340 are shown by one black star and two black stars, respectively. (B) Possible alternative splicing regions of the SF-RDL gene correspond to exon 3 and exon 6 of the Drosophila Rdl gene. Amino acids that differed among possible alternative exons (3a, 3b, 3b', 6c, and 6d) are shown in bold and underlined.

GABA receptor in fipronil-resistant S. furcifera, Drosophila Mel-2 cells were transfected with expression plasmids containing wild-type/A2'N SF-RDL, wild-type/A2'N·R340Q SFRDL, or wild-type/R340Q SF-RDL genes.

We found S35A and R347W mutations. Although the R340Q mutation appeared many times by using several independent PCR assays, S35A and R347W mutations appeared only once. Because of the possibility that these mutations were introduced by PCR error, the mutations were not studied.

3. Influence of the $A 2^{\prime} N$ mutation on $G A B A$ and fipronil sensitivities

The $\mathrm{EC}_{50}$ values of GABA for wild-type and $\mathrm{A} 2^{\prime} \mathrm{N}$ mutant SFRDL homomers were $0.25 \pm 0.08 \mu \mathrm{M}$ and $5.63 \pm 0.66 \mu \mathrm{M}$, respectively (Table 1), indicating that the $A 2^{\prime} \mathrm{N}$ mutation caused
Table 1. GABA sensitivity of Drosophila Mel-2 cells transfected with wild-type or mutant SF-RDL genes, either individually or together

\begin{tabular}{lcc}
\hline \multicolumn{1}{c}{ SF-RDL } & $\mathrm{EC}_{50}(\mu \mathrm{M})$ & Hill coefficient \\
\hline Wild-type & $0.25 \pm 0.08$ & $1.66 \pm 0.24$ \\
$\mathrm{~A} 2^{\prime} \mathrm{N}$ & $5.63 \pm 0.66$ & $1.82 \pm 0.53$ \\
$\mathrm{~A} 2^{\prime} \mathrm{N} \cdot \mathrm{R} 340 \mathrm{Q}$ & $6.00 \pm 1.00$ & $1.50 \pm 0.05$ \\
$\mathrm{R} 340 \mathrm{Q}$ & $1.29 \pm 0.32$ & $2.45 \pm 0.24$ \\
Wild-type/A2 ${ }^{\prime} \mathrm{N}$ & $0.37 \pm 0.10$ & $1.24 \pm 0.04$ \\
Wild-type/A2 ${ }^{\prime} \mathrm{N} \cdot \mathrm{R} 340 \mathrm{Q}$ & $0.83 \pm 0.10$ & $1.36 \pm 0.36$ \\
Wild-type/R340Q & $0.32 \pm 0.13$ & $1.92 \pm 0.66$ \\
\hline
\end{tabular}

Data are shown as the mean \pm SEM. 


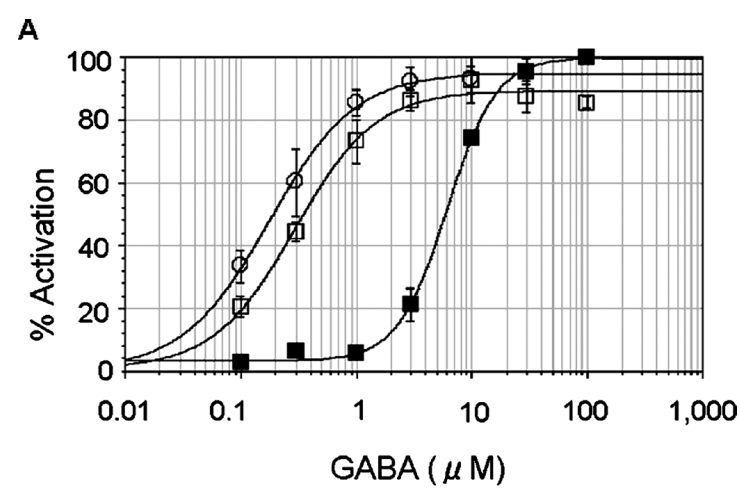

B

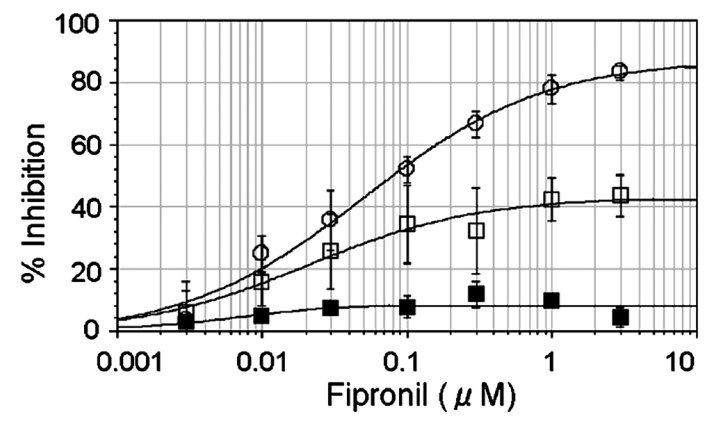

Fig. 2. Influence of the $A 2^{\prime} \mathrm{N}$ mutation on $\mathrm{GABA}$ and fipronil sensitivities. (A) Concentration-response curves for GABA. Data are expressed as a percentage of the maximal response to GABA of wild-type SF-RDL homomers (open circle), A2' $\mathrm{N}$ mutant SF-RDL homomers (closed square), and GABA receptors on cells co-transfected with wild-type and $A 2^{\prime} \mathrm{N}$ mutant SF-RDL genes (open square). Vertical bars represent the SEM. (B) Concentration-response curves for the inhibitory effects of fipronil on wild-type SF-RDL homomers (open circle), A2'N mutant SF-RDL homomers (closed square), and GABA receptors in cells co-transfected with wild-type and $\mathrm{A} 2^{\prime} \mathrm{N}$ mutant SF-RDL genes (open square). The inhibitory effects of fipronil on the response to the $\mathrm{EC}_{80}$ concentrations of $\mathrm{GABA}$ are shown as the percentage different from control cells in the absence of fipronil. Vertical bars represent the SEM.

decreased activation by GABA. When cells were co-transfected with wild-type and $\mathrm{A} 2^{\prime} \mathrm{N}$ mutant SF-RDL genes, the $\mathrm{EC}_{50}$ value of GABA for GABA receptors on co-transfected cells was $0.37 \pm 0.10 \mu \mathrm{M}$ (Table 1 ), showing that the concentrationresponse curve for GABA of the GABA receptors on co-transfected cells is similar to that of the wild-type SF-RDL homomers (Fig. 2A).

Fipronil inhibited the wild-type SF-RDL homomers with an $\mathrm{IC}_{50}$ of $79 \pm 46 \mathrm{nM}$. GABA receptors on co-transfected cells were inhibited up to $40 \%$ by $3 \mu \mathrm{M}$ of fipronil, although $\mathrm{A} 2^{\prime} \mathrm{N}$ mutant SF-RDL homomers were not at all inhibited by $3 \mu \mathrm{M}$ of fipronil (Fig. 2B).

4. Influence of the $A 2^{\prime} N$ and $R 340 Q$ double mutation on $G A B A$ and fipronil sensitivities

The $\mathrm{EC}_{50}$ value of GABA for A2'N.R340Q double-mutant SFRDL homomers was $6.00 \pm 1.00 \mu \mathrm{M}$ (Table 1), indicating that the $\mathrm{A} 2^{\prime} \mathrm{N} \cdot \mathrm{R} 340 \mathrm{Q}$ mutation caused the decreased activation by
A

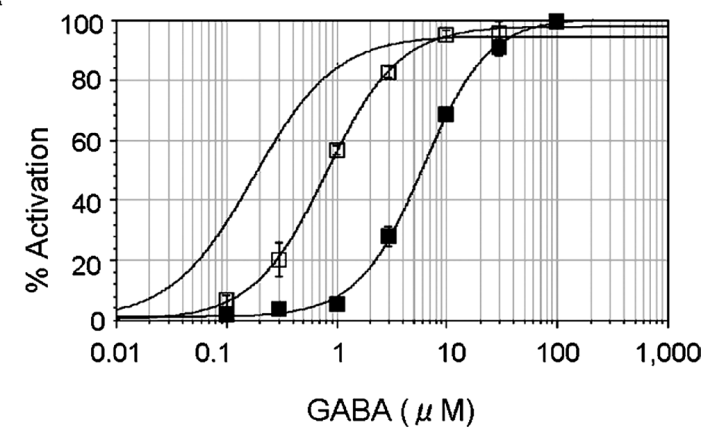

B

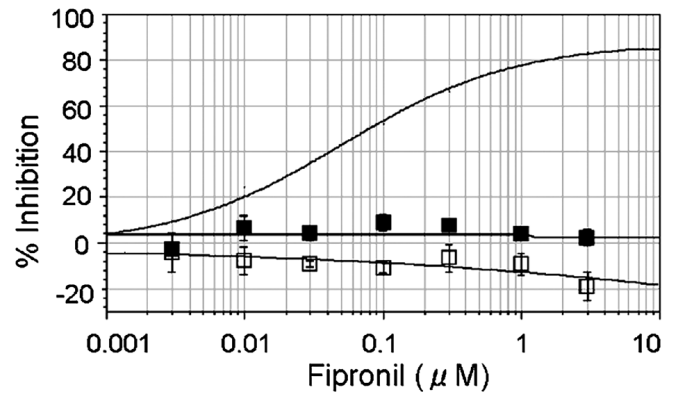

Fig. 3. Influence of the $A 2^{\prime} \mathrm{N} \cdot \mathrm{R} 340 \mathrm{Q}$ double mutation on GABA and fipronil sensitivities. (A) Concentration-response curves for GABA. Data are expressed as a percentage of the maximal response to GABA of A2' $\mathrm{N} \cdot \mathrm{R} 340 \mathrm{Q}$ mutant SF-RDL homomers (closed square) and GABA receptors on cells co-transfected with wild-type and A2 ${ }^{\prime} \mathrm{N} \cdot \mathrm{R} 340 \mathrm{Q}$ mutant SF-RDL genes (open square). For comparison, the concentrationresponse curve for the GABA of wild-type SF-RDL homomers is also represented by a line. Vertical bars represent the SEM. (B) Concentrationresponse curves for the inhibitory effects of fipronil on $A 2^{\prime} \mathrm{N} \cdot \mathrm{R} 340 \mathrm{Q}$ mutant SF-RDL homomers (closed square) and GABA receptors on cells co-transfected with wild-type and A2'N-R340Q mutant SF-RDL genes (open square). For comparison, a concentration-response curve for fipronil of wild-type SF-RDL homomers is also represented by a line. The inhibitory effects of fipronil on the response to the $\mathrm{EC}_{80}$ concentrations of GABA are shown as the percentage different from control cells in the absence of fipronil. Vertical bars represent the SEM.

GABA. When cells were co-transfected with wild-type and $\mathrm{A} 2^{\prime} \mathrm{N} \cdot \mathrm{R} 340 \mathrm{Q}$ double-mutant SF-RDL genes, the $\mathrm{EC}_{50}$ value of GABA for the GABA receptors expressed on co-transfected cells was $0.83 \pm 0.10 \mu \mathrm{M}$ (Table 1 ), showing that the concentration-response curve for GABA shifted to lower concentrations by co-transfection (Fig. 3A).

Unlike the $A 2^{\prime} \mathrm{N}$ single mutation, fipronil had no inhibitory effect on GABA receptors in the cells transfected with the A2'N-R340Q double-mutant SF-RDL gene with or without the wild-type SF-RDL gene (Fig. 3B).

Negative values of inhibition were observed in cells cotransfected with wild-type and A2'N.R340Q SF-RDL genes, suggesting that the high concentration of fipronil facilitated the activation by GABA. The dual action of dieldrin on the GABA receptor was reported by the whole-cell patch-clamp technique using cockroach neurons. ${ }^{23)}$ To confirm the potenti- 
ating action of fipronil on wild-type/A2'N-R340Q SF-RDL, studies using the whole-cell patch-clamp technique will be required.

5. Influence of the R340Q mutation on GABA and fipronil sensitivities

To examine the influence of the R340Q single mutation, a R340Q mutant SF-RDL was constructed, although the R340Q single mutation was not found in clones isolated from $S$. furcifera.

The $\mathrm{EC}_{50}$ value of GABA for R340Q mutant SF-RDL homomers was $1.29 \pm 0.32 \mu \mathrm{M}$ (Table 1), indicating that the R340Q mutation caused the decreased activation by GABA. When cells were co-transfected with wild-type and R340Q mutant SF-RDL genes, the $\mathrm{EC}_{50}$ value of GABA for GABA receptors on co-transfected cells was $0.32 \pm 0.13 \mu \mathrm{M}$ (Table 1 ), showing that the concentration-response curve for GABA of

A

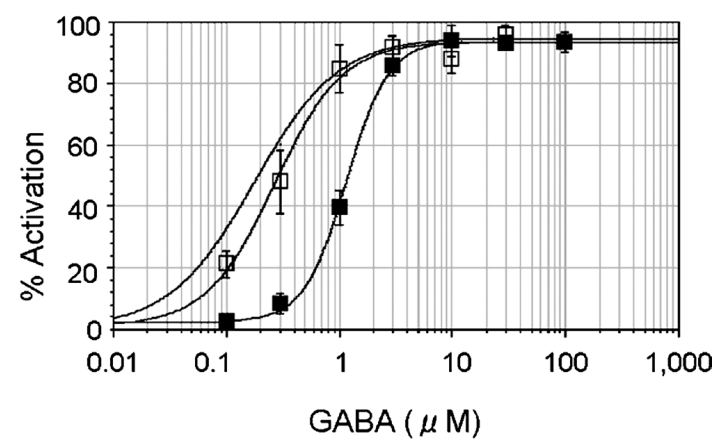

B

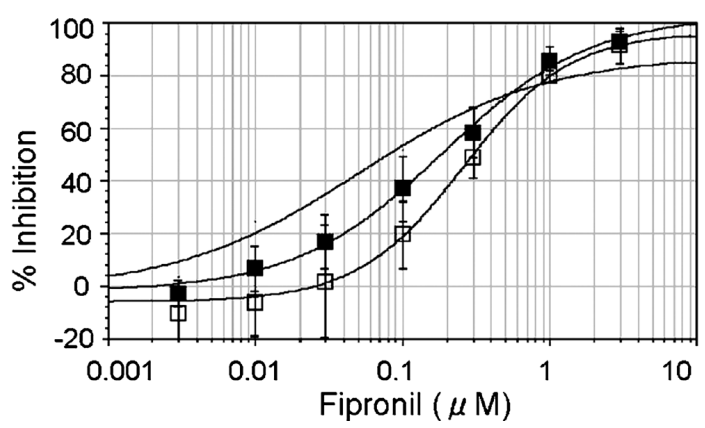

Fig. 4. Influence of the R340Q mutation on GABA and fipronil sensitivities. (A) Concentration-response curves for GABA. Data are expressed as a percentage of the maximal response to GABA of R340Q mutant SF-RDL homomers (closed square) and GABA receptors in cells co-transfected with wild-type and R340Q mutant SF-RDL genes (open square). For comparison, a concentration-response curve for the GABA of wild-type SF$\mathrm{RDL}$ homomers is also represented by a line. Vertical bars represent the SEM. (B) Concentration-response curves for the inhibitory effects of fipronil on R340Q mutant SF-RDL homomers (closed square) and GABA receptors on cells co-transfected with wild-type and R340Q mutant SF$\mathrm{RDL}$ genes (open square). For comparison, the concentration-response curve for fipronil of wild-type SF-RDL homomers is also represented by a line. The inhibitory effects of fipronil on the response to the $\mathrm{EC}_{80}$ concentrations of GABA are shown as the percentage different from control cells in the absence of fipronil. Vertical bars represent the SEM. the GABA receptors on co-transfected cells shifted to the left (Fig. 4A).

The $\mathrm{IC}_{50}$ values for GABA receptors on cells transfected with the R340Q mutant SF-RDL gene with and without the wild-type SF-RDL gene were $266 \pm 155 \mathrm{nM}$ and $204 \pm 149 \mathrm{nM}$, respectively, showing that the influence of the R340Q single mutation on fipronil sensitivity was modest (Fig. 4B).

\section{Discussion}

In a previous study, ${ }^{20)}$ sequence analysis of about 0.9-kbp DNA encoding the M1-M3 membrane-spanning region of SF-RDL from fipronil-susceptible and -resistant $S$. furcifera identified the $\mathrm{A} 2^{\prime} \mathrm{N}$ mutation. The membrane potential assay using Drosophila Mel-2 cells stably expressing wild-type and $\mathrm{A}^{\prime} \mathrm{N}$ mutant Drosophila RDL GABA receptors suggested that the A2 ${ }^{\prime} \mathrm{N}$ mutation conferred fipronil resistance.

To better understand the mechanisms of fipronil resistance in $S$. furcifera, we isolated and sequenced full-length cDNA clones encoding SF-RDL from fipronil-susceptible and -resistant $S$. furcifera. In addition to the $\mathrm{A} 2^{\prime} \mathrm{N}$ mutation, a novel R340Q mutation was found in the cytoplasmic loop between M3 and M4. The R340Q mutation was only found in cDNA clones carrying the $A 2^{\prime} \mathrm{N}$ mutation. As the $\mathrm{A} 2^{\prime} \mathrm{N}$ mutation was suggested to be heterozygous, ${ }^{20,21)}$ Drosophila Mel- 2 cells were transfected with expression plasmids containing wildtype/A2'N SF-RDL, wild-type/A2'N-R340Q SF-RDL, or wildtype/R340Q SF-RDL genes.

Decreased activation by GABA in $\mathrm{A} 2{ }^{\prime} \mathrm{N}$ SF-RDL and A $2^{\prime} \mathrm{N} \cdot \mathrm{R} 340 \mathrm{Q}$ SF-RDL homomers (Figs. 2A and 3A, respectively) might be disadvantageous and related to the heterozygous state of the $\mathrm{A} 2^{\prime} \mathrm{N}$ mutation in fipronil-resistant $S$. furcifera. However, the synaptic GABA contents have been reported to be $1.5-3 \mathrm{mM},{ }^{24)}$ and this concentration range of GABA is much higher than the $\mathrm{EC}_{50}$ values for $\mathrm{A} 2^{\prime} \mathrm{N}$ SF-RDL and $A 2^{\prime} \mathrm{N} \cdot \mathrm{R} 340 \mathrm{Q}$ SF-RDL homomers. Further study is required to understand why $S$. furcifera with the homozygous state of the $\mathrm{A} 2^{\prime} \mathrm{N}$ mutation has not been found.

The $\mathrm{A} 2^{\prime} \mathrm{N}$ mutant SF-RDL and $\mathrm{A} 2^{\prime} \mathrm{N} \cdot \mathrm{R} 340 \mathrm{Q}$ double-mutant SF-RDL homomers were not inhibited by fipronil (Figs. $2 \mathrm{~B}$ and $3 \mathrm{~B}$, respectively). However, fipronil sensitivity differed between heterozygous wild-type/A2'N SF-RDL and heterozygous wild-type/A2'N·R340Q SF-RDL. Unlike heterozygous wild-type/A2'N-R340Q SF-RDL, heterozygous wild-type/ A2' N SF-RDL did not completely abolish the inhibitory effect of fipronil. The ratio of fipronil-susceptible and -resistant receptors seems to be important for fipronil sensitivity in heterozygous expression. The R340Q mutation may alter this ratio by influencing the expression levels or assembly of receptors. It is interesting to note that the cytoplasmic loop between M3 and M4 of the mammalian GABA receptor is known to play a role in receptor trafficking and activity through control of surface expression. $^{25-28)}$ The T350M mutation in the RDL GABA receptor from $D$. simulans is located at the boundary of the M3 membrane-spanning region and the cytoplasmic loop between 
M3 and M4 and influenced fipronil sensitivity. ${ }^{15)}$ However, the role of the T350M mutation in fipronil resistance seems to be different from the role of the R340Q mutation because the T350M single mutation affected the fipronil sensitivity at the homozygous state, whereas the influence of the R340Q single mutation on the fipronil sensitivity was not significant (Fig. 4B).

Although results showed that the influence of the $\mathrm{A} 2^{\prime} \mathrm{N} \cdot \mathrm{R} 340 \mathrm{Q}$ mutation on fipronil resistance was more profound than that of the $\mathrm{A} 2^{\prime} \mathrm{N}$ single mutation in the heterozygous expression system used in this study, it is unknown whether a higher level of fipronil-resistant $S$. furcifera carries the $\mathrm{A} 2^{\prime} \mathrm{N} \cdot \mathrm{R} 340 \mathrm{Q}$ double mutation. Studies exploring the in vitro and in vivo expression level and the assembly of receptors will be needed. In this study, we attached the flag tag to the Cterminal of wild-type SF-RDL and added the V5 tag to the C-terminal of mutant SF-RDL to investigate the expression level of receptors. However, we could not obtain reliable results from the immunostaining of cells expressing tag-attached receptors because of low signal (data not shown). To show that the $\mathrm{A} 2^{\prime} \mathrm{N} \cdot \mathrm{R} 340 \mathrm{Q}$ double mutation confers a higher level of fipronil resistance than the $\mathrm{A} 2^{\prime} \mathrm{N}$ single mutation in $S$. furcifera, further studies are required.

Furthermore, the small brown planthopper L. striatellus has developed fipronil resistance. We identified the $A 2^{\prime} \mathrm{N}$ mutation in LS-RDL. ${ }^{21)}$ Moreover, the $\mathrm{A} 2^{\prime} \mathrm{N}$ mutation in LS-RDL was suggested to be a heterozygous mutation. A membrane potential assay showed that fipronil had no inhibitory effect at $10 \mu \mathrm{M}$ on cells transfected with the $\mathrm{A} 2^{\prime} \mathrm{N}$ mutant LS-RDL gene with or without the wild-type LS-RDL gene. ${ }^{21)}$ In the case of LS-RDL, the A2' $\mathrm{N}$ single mutation was sufficient to abolish the inhibitory effect of fipronil in heterozygous expression. Because the R340Q mutation was not found in 6 clones from fipronil-resistant L. striatellus (data not shown), the influence of the R340Q mutation may be specific for SF-RDL.

In addition, glutamate-gated chloride channels (GluCls) are targets of fipronil in insects. ${ }^{29,30)}$ However, it is disputable whether $\mathrm{GluCl}$ subunits co-assemble with GABA receptor subunits. ${ }^{31-34)}$ It is not known whether the A2' $\mathrm{N}$ mutant SFRDL or the A2' N-R340Q mutant SF-RDL co-assembles with $\mathrm{GluCl}$ subunits and affects sensitivity to fipronil, but the effects of fipronil on GluCls can be considered an important factor affecting fipronil resistance.

In conclusion, we found a novel R340Q mutation in SFRDL. This mutation was located in the cytoplasmic loop between M3 and M4 and was found only in clones carrying the $\mathrm{A} 2^{\prime} \mathrm{N}$ mutation; the $\mathrm{A} 2^{\prime} \mathrm{N}$ mutation was suggested to confer fipronil resistance and to be expressed in a heterozygous state. A membrane potential assay showed that the influence of the A $2^{\prime} \mathrm{N} \cdot \mathrm{R} 340 \mathrm{Q}$ double mutation on fipronil resistance was more profound than that of the $A 2^{\prime} \mathrm{N}$ single mutation in the heterozygous expression of wild-type and mutant SF-RDL genes. Our finding of the $\mathrm{A} 2^{\prime} \mathrm{N} \cdot \mathrm{R} 340 \mathrm{Q}$ double mutation of SF-RDL will be useful in understanding the mechanisms and develop- ment of fipronil resistance in S. furcifera.

\section{Acknowledgments}

The authors thank Ms. A. Naoi (Mitsui Chemicals Agro) for providing fipronil-susceptible and -resistant S. furcifera.

\section{References}

1) R. H. ffrench-Constant, D. P. Mortlock, C. D. Shaffer, R. J. MacIntyre and R. T. Roush: Proc. Natl. Acad. Sci. USA 88, 7209-7213 (1991).

2) R. H. ffrench-Constant and T. A. Rocheleau: J. Neurochem. 60, 23232326 (1993).

3) C. Miller: Neuron 2, 1195-1205 (1989).

4) L. Chen, K. A. Durkin and J. E. Casida: Proc. Natl. Acad. Sci. USA 103, 5185-5190 (2006).

5) J. E. Casida and M. Tomizawa: J. Pestic. Sci. 33, 4-8 (2008).

6) K. Hisano, F. Ozoe, J. Huang, X. Kong and Y. Ozoe: Invert. Neurosci. 7, 39-46 (2007).

7) R. H. ffrench-Constant, T. A. Rocheleau, J. C. Steichen and A. E. Chalmers: Nature 363, 449-451 (1993).

8) N. Anthony, T. Unruh, D. Ganser and R. ffrench-Constant: Mol. Gen. Genet. 260, 165-175 (1998).

9) C. Bass, I. Schroeder, A. Turberg, L. M. Field and M. S. Williamson: Pest. Manag. Sci. 60, 1157-1162 (2004).

10) W. Du, T. S. Awolola, P. Howell, L. L. Koekemoer, B. D. Brooke, M. Q. Benedict, M. Coetzee and L. Zheng: Insect. Mol. Biol. 14, 179-183 (2005).

11) J. -R. Gao, T. Kozaki, C. A. Leichter, F. D. Rinkevich, T. Shono and J. G. Scott: Pestic. Biochem. Physiol. 88, 66-70 (2007).

12) M. Miyazaki, F. Matsumura and R. W. Beeman: Comp. Biochem. Physiol. 111B, 399-406 (1995).

13) M. Thompson, J. C. Steichen and R. H. ffrench-Constant: Insect. Mol. Biol. 2, 149-154 (1993).

14) M. Hope, M. Menzies and D. Kemp: J. Econ. Entomol. 103, 13551359 (2010).

15) G. L. Goff, A. Hamon, J. -B. Berg and M. Amichot: J. Neurochem. 92, 1295-1305 (2005).

16) M. Matsumura, H. Takeuchi, M. Satoh, S. Sanada-Morimura, A. Otuka, T. Watanabe and D. V. Thanh: Pest. Manag. Sci. 64, 11151121 (2008).

17) M. Matsumura, H. Takeuchi, M. Satoh, S. Sanada-Morimura, A. Otuka, T. Watanabe and D. V. Thanh: "Current Status of Insecticide Resistance in Rice Planthoppers in Asia," ed. By K .L. Heong and B. Hardy, Rice International Institute, Los Banos, Philippines, pp. 233244 (2009).

18) M. Matsumura: Plant Prot. 63, 745-748 (2009).

19) A. Otuka, M. Matsumura, S. Sanada-Morimura, H. Takeuchi, T. Watanabe, R. Ohtsu and H. Inoue: Appl. Entomol. Zool. 45, 259-266 (2010).

20) T. Nakao, A. Naoi, N. Kawahara and K. Hirase: Pestic. Biochem. Physiol. 97, 262-266 (2010).

21) T. Nakao, A. Kawase, A. Kinoshita, R. Abe, M. Hama, N. Kawahara, and K. Hirase: J. Econ. Entomol. 104, 646-652 (2011).

22) K. Narusuye, T. Nakao, R. Abe, Y. Nagatomi, K. Hirase and Y. Ozoe: Insect. Mol. Biol. 16, 723-733 (2007).

23) X. Zhao, V. L. Salgado, J. Z. Yeh and T. Narahashi: J. Pharmacol. Exp. Ther. 306, 914-924 (2003).

24) V. Tretter and S. J. Moss: Front. Mol. Neurosci. 1, 1-13 (2008).

25) C. N. Connolly, J. T. Kittler, P. Thomas, J. M. Uren, N. J. Brandon, T. 
G. Smart and S. J. Moss: J. Biol. Chem. 274, 36565-36572 (1999).

26) J. N. Jovanovic, P. Thomas, J. T. Kittler, T. G. Smart and S. J. Moss: J. Neurosci. 24, 522-530 (2004).

27) A. Mizokami, T. Kanematsu, H. Ishibashi, T. Yamaguchi, I. Tanida, K. Takenaka, K. I. Nakayama, K. Fukami, T. Takenawa, E. Kominami, S. J. Moss, T. Yamamoto, J. Nabekura and M. Hirata: J. Neurosci. 27, 1692-1701 (2007).

28) W.-Y. Lo, E. J. Botzolakis, X. Tang and R. L. Macdonald: J. Biol. Chem. 283, 29740-29752 (2008).

29) X. Zhao, J. Z. Yeh, V. L. Salgado and T. Narahashi: J. Pharmacol. Exp. Ther. 310, 192-201 (2004).

30) T. Narahashi, X. Zhao, T. Ikeda, V. L. Salgado and J. Z. Yeh: Pestic.
Biochem. Physiol. 97, 149-152 (2010).

31) S. W. Ludmerer, V.A. Warren, B. S. Williams, Y. Zheng, D. C. Hunt, M. B. Ayer, M. A. Wallace, A. G. Chaudhary, M. A. Egan, P. T. Meinke, D. C. Dean, M. L. Garcia, D. F. Cully and M. M. Smith: Biochemistry 41, 6548-6560 (2002).

32) X. Zhao and V. L. Salgado: Pestic. Biochem. Physiol. 97, 153-160 (2010).

33) D. F. Cully, P. S. Paress, K. K. Liu, J. M. Schaeffer and J. P. Arena: J. Biol. Chem. 271, 20187-20191 (1996).

34) Y. Eguchi, M. Ihara, E. Ochi, Y. Shibata, K. Matsuda, S. Fushiki, H. Sugama, Y. Hamasaki, H. Niwa, M. Wada, F. Ozoe and Y. Ozoe: Insect Mol. Biol. 15, 773-783 (2006). 